\title{
User Motivation and Technology Acceptance in Online Learning Environments
}

\author{
Maxime Pedrotti $^{1(\sqrt{(-)})}$ and Nicolae Nistor ${ }^{1,2}$ \\ ${ }^{1}$ Ludwig-Maximilians-Universität München, Munich, Germany \\ \{maxime.pedrotti,nic.nistor\} almu.de \\ 2 Walden University, Minneapolis, USA
}

\begin{abstract}
Research on technology acceptance in educational contexts often shows little or no influence of user acceptance on use intention or use behavior. While recent attempts to factor in learners' motivation appear promising, the problem of limited explanatory value of technology acceptance models remains. This paper further explores the relationship between motivational and acceptance factors in different learning contexts. Data $(\mathrm{N}=673)$ from four studies conducted among users of two online learning environments at a major university in Germany are analyzed using a combined data set containing items relating to user motivation (according to Self-Determination Theory) and technology acceptance (according to the Unified Theory of Acceptance and Use of Technology). The data show significant differences in acceptance and motivational levels between these four groups, as well as a connection between acceptance and motivation. Implications of these results include a recommendation to revisit UTAUT assumptions and variables in future research.
\end{abstract}

Keywords: Motivation - Technology acceptance - Learning environment · $\mathrm{UTAUT} \cdot \mathrm{SDT}$

\section{Introduction}

While learning technologies such as online lecture videos (OLV) or online learning environments such as Moodle have received much attention in recent years, particularly with recent developments of Massive Open Online Courses (MOOCs) and with universities trying to provide a modern learning environment, the question of how (potential) users view any new learning technology, what their attitudes towards new technologies are, and how these factors influence their use behavior, remains a difficult subject. A very popular acceptance approach is taken from Information Systems (IS) research. However, unlike in IS, technology acceptance models regularly fail to be reproduced in educational contexts. This paper aims to address this problem by refining the view on motivational variables, which have been shown to have a strong influence on learning activities. By analyzing data from four different studies conducted at a major university in Germany, we hope to show the importance of including additional variables measuring a person's motivation, so as to better understand a person's attitudes towards learning technologies, and how learning behavior can be supported by such technologies. 


\section{Technology Acceptance in Educational Contexts}

One of the most prominent models to explain the use of technological solutions in professional contexts was proposed by Venkatesh et al. in 2003 with the Unified Theory of Acceptance and Use of Technology (UTAUT) [1]. According to their research, which they base on various already popular and established technology acceptance models, four main factors influence a person's intention to actually make use of a proposed technological tool: performance expectancy (PE), effort expectancy (EE), facilitating conditions (FC) and social influence (SI). The first two variables are best described as expectations a person may have towards the benefits gained from using the technology at hand. The more someone hopes to achieve through the use of the tool, the higher the value of PE. The less effort someone expects to have to put to a certain task using a certain technology, the higher the value of EE. In terms of cost and benefit: PE describes how much benefit a person hopes to gain; EE describes how much the same person hopes to reduce costs. FC and SI describe contextual concepts concerning the institutional and social surroundings of a person. While facilitating conditions are the conditions set by the institutional surrounding (e.g. employer of a person, university someone is enrolled in, etc.), social influence is derived from people within the direct social environment of a person and their attitudes towards the technology in question.

According to the UTAUT model, these four factors directly influence a person's intention to use a certain technological solution to achieve work related goals. Drawing from the Theory of Planned Behavior (TPB) [2], the UTAUT model then proposes a following influence from use intention to actual use behavior.

In summary, the Unified Theory proposed by Venkatesh et al. aims to include individual factors (PE and EE, i.e. cost and benefit) as well as social (SI) and institutional ones (FC). The inclusion of the TPB model allows for a final differentiation between use intention and actual use behavior, since not all intention necessarily lead to execution of said intent.

The UTAUT model has been applied in various studies since its first formulation, and empirical evidence shows strong support in workplace environments when analyzing attitudes towards work tools. However, when applied in educational context, specifically in higher education, studies have difficulties reproducing the theorized influences proposed in UTAUT [3, 4].

One major difference between workplace and educational settings is the motivational aspect of people's behavior. Typically, behavior in the workplace is driven by extrinsic motivators, e.g. salary, hierarchical position within an organization, social status, etc. Whereas in educational settings intrinsic motivators play a much more important role determining a person's positive learning behavior than in typical workplace settings [5,6].

Self-Determination Theory (SDT) [7] proposes a view on a person's motivational attitude as a spectrum determined by the level of autonomy they feel they have over their decision making process. The more freedom someone feels, i.e. the more they feel self-determined in making a decision, the more likely they will be intrinsically motivated in their behavior. The motivational spectrum ranges from amotivation, where decisions are made without any amount of self-determination, through four stages of (semi-)extrinsic motivations - defined by the level and type of so-called "regulation", 
i.e. external control factors - up to a state of absolute autonomy in making a decision, described as intrinsic motivation.

UTAUT already includes motivational aspects, albeit primarily extrinsic motivators (i.e. cost and benefit from using a certain technology). Following the premise of SDT, however, a comprehensive model should also include the rest of the spectrum (i.e. intrinsic motivation and amotivation). Another interesting point could be made in analyzing the relationship between technology acceptance and motivation in general: Is motivation a part of technology acceptance? Is it one of the factors contributing to use intention or use behavior? Are motivation and technology acceptance actually two separate concepts which should be distinguished from one another? These questions suggest revisiting the original UTAUT model to analyze the relationship between motivational and acceptance factors influencing use behavior, especially - but not only so - in educational settings.

\section{Comparative Study of Different Learning Environments}

Data from four previously conducted survey studies were combined to create one combined data set for this analysis. Two studies (A \& C) were conducted amongst users of a faculty-wide online learning management system in 2013 and in 2014. The other two studies (B \& D) were conducted amongst users of an OLV system in 2013 and 2015. Studies A, B, and C administered online questionnaires within the respective learning environment, in study D pen-and-paper questionnaires were distributed during a lecture which was being recorded and made available online through the OLV system in question. All four studies were conducted at the same major German university, focused on aspects of technology acceptance and user motivation, and in all questionnaires participants were confronted with the same question items concerning their attitudes towards the respective online learning environment (variation only in the name of the respective online system); therefore, a joint analysis in a combined data set was possible. This combination of four different measurements in two different online learning environments with different educational settings was chosen to compare the differences in motivation and corresponding differences in technology acceptance. Study A yielded 251 valid cases, study B 210 cases, study C 100 cases, and study D 112 cases - the complete data set therefore consists of 673 responses from all four studies. $79.3 \%$ participants were female, $16.9 \%$ were male (3.6\% with missing values), the average age was 24 $(\mathrm{N}=638, \mathrm{M}=24.28, \mathrm{SD}=6.43)$. While the gender distribution may seem unnaturally skewed towards female participants, however, registration numbers at this particular university show a general majority (about $60 \%$ ) of female students, the percentage being even higher in courses for pedagogy, psychology, and teacher education, where most users of the learning systems in this analysis are located. Thus, we do not expect much of an impact on the following results.

The variables from UTAUT and SDT were measured using four questionnaire items each. The questions for UTAUT constructs were adapted from the original study by Venkatesh et al. [1], while the questions for motivational concepts were adapted from a study by Standage et al. [8], which in turn are based on the Academic 
Motivation Scale [9]. Due to constraints of the combined data set, the following analysis will focus on three of the theorized aspects of motivation: intrinsic motivation (IM), identified regulation (IR), and amotivation (AM). The exclusion of further aspects of extrinsic motivation was necessary, since not all four studies measured all these sub-concepts, or used different questionnaire items to determine the motivation of participants. Therefore, only variables present in all four studies and measured with the same questionnaire items were included in this analysis.

The following analysis consists of two main steps: First, a confirmatory factor analysis using a principal component analysis (PCA) was performed to assess the validity of the scales proposed by UTAUT and SDT. Second, a variance analysis (one-way ANOVA) was performed to compare the mean values between the four studies. All statistical calculations were made with IBM SPSS 23 for Windows.

The PCA confirmed six factors with a total of $72.68 \%$ explained variance. The Kaiser-Meyer-Olkin Measure of Sampling Adequacy is well within the accepted range $(\mathrm{KMO}=.918)$, together with the results from Bartletts's Test of Sphericity (Approx. Chi-Square $=11125,354$, df $=378, \mathrm{p}<.001$ ) we can interpret the results as a valid factor analysis. Results from the rotated component matrix (Varimax rotation) indicate a few items have to be omitted due to weak or cross-loading. Most notably, items for facilitating conditions do not form a single coherent factor, but show factor loadings towards one or more of the other identified constructs. Social influence, on the other hand, appears to form two distinct factors with strong loadings from their respective items. Looking at the corresponding questions in the questionnaires, the two factors can be interpreted as Social influence coming from the institutional surrounding (i.e. university and professors), and social influence coming from personal surroundings (i.e. friends, fellow students, etc.). The eight items indicating measures for intrinsic motivation and identified regulation show strong loading values towards one factor, which will be considered as "Motivation" in the following analysis. To summarize, the six factors identified and confirmed by way of PCA are: Motivation (F1MO), Effort Expectancy (F2EE), Performance Expectancy (F3PE), Amotivation (F4AM), Social Influence by the Institution (F5IS), and Social Influence by Peers (F6PS). A reliability analysis shows high values of Cronbach's Alpha throughout the identified scales: Alpha values range from .919 through .944 for the first five constructs, while F6PS yields only .780, though it is still within the acceptable range of $>.7$. The scales can assume values ranging from 1 through 7, where high values represent a strong foundation of the concept in a person's attitudes. Over all four studies, participants average high expectations towards performance gain and effort minimization. They feel moderately motivated $(\mathrm{M}=3.41$, $\mathrm{SD}=1.53)$, moderately supported by their institution in using the respective technology $(\mathrm{M}=3.90, \mathrm{SD}=1.99)$, but a little stronger by their peers $(\mathrm{M}=4.31, \mathrm{SD}=1.58)$. The ANOVA results show statistically significant differences between groups for all UTAUT and SDT variables. Since the data did not meet the requirement of variance homogeneity within the studies (as determined by Levene test for variance homogeneity), a Welch F-Test was computed, as presented in Table 1. 
Table 1. ANOVA results (Welch F-Test)

\begin{tabular}{l|l|l|l|c}
\hline Robust tests of equality of means & \multicolumn{5}{l}{} \\
\hline & Statistic $^{\mathrm{a}}$ & df1 & df2 & Sig. \\
\hline F1MO Motivation & 18,060 & 3 & 280,432 &, 000 \\
\hline F2EE Effort Expectancy & 404,819 & 3 & 269,498 &, 000 \\
\hline F3PE Performance Expectancy & 202,390 & 3 & 274,425 &, 000 \\
\hline F4AM Amotivation & 544,554 & 3 & 243,642 &, 000 \\
\hline F5IS Institutional Support & 40,953 & 3 & 264,728 &, 000 \\
\hline F6PS Peer Support & 113,892 & 3 & 294,574 &, 000 \\
\hline
\end{tabular}

${ }^{a}$ Asymptotically F distributed.

A post-hoc Scheffé test was performed to assess differences between the four studies concerning the different variables. Participants from study A exhibited the lowest average value for motivation of all four studies $(\mathrm{M}=2.91, \mathrm{SD}=1.57)$ and the lowest institutional support $(\mathrm{M}=3.04, \mathrm{SD}=1.71)$. Peer support and Effort Expectancy were relatively high, though not the highest of all four groups. Participants from study $\mathrm{B}$ showed very high values for $\mathrm{EE}$ and $\mathrm{PE}(\mathrm{M}=6.30, \mathrm{SD}=.74 ; \mathrm{M}=6.16, \mathrm{SD}=1.03)$, while also showing high values of institutional support $(\mathrm{M}=4.90, \mathrm{SD}=1.82)$ and very low values of amotivation $(\mathrm{M}=1.17, \mathrm{SD}=.47)$. Study $\mathrm{C}$ showed the lowest values for $\mathrm{EE}$ and $\mathrm{PE}(\mathrm{M}=2.47, \mathrm{SD}=.97 ; \mathrm{M}=2.82, \mathrm{SD}=1.32)$, while yielding the highest values for amotivation $(\mathrm{M}=6.00, \mathrm{SD}=1.16)$.

\section{Discussion and Conclusion}

The purpose of this paper was to illustrate the need for a more inclusive approach to technology acceptance research in educational contexts. We propose revisiting the UTAUT and including an autonomy-based view on motivation following the concept of Self-determination Theory, and the inclusion of intrinsic motivation as well as amotivation into traditional acceptance models, to better understand the attitudes of people using learning technologies such as online learning management systems.

Results from an ANOVA show statistically significant differences between different learning contexts. Institutional support appears to coincide with decreased amotivation amongst participants as well as their expectations of reduced effort and increased learning performance. On the other hand, moderate to low social support appears to be linked to high amotivation as well as low gain expectations from using the system. These results - while not yet an in-depth analysis of the statistical connections - are indicative of a possible link between autonomy-based constructs of motivation and the acceptance of technological solutions to assist learning. Future research should therefore include such measures and further investigate the connections between users' motivation and their acceptance of technology, as well as the combined influence on their use intentions and their use behavior. With such detailed insight, (online) learning environment as well as the corresponding learning scripts coming from educators could be adapted to increase the success of technology enhanced learning. 
Open Access. This chapter is distributed under the terms of the Creative Commons Attribution 4.0 International License (http://creativecommons.org/licenses/by/4.0/), which permits use, duplication, adaptation, distribution and reproduction in any medium or format, as long as you give appropriate credit to the original author(s) and the source, a link is provided to the Creative Commons license and any changes made are indicated.

The images or other third party material in this chapter are included in the work's Creative Commons license, unless indicated otherwise in the credit line; if such material is not included in the work's Creative Commons license and the respective action is not permitted by statutory regulation, users will need to obtain permission from the license holder to duplicate, adapt or reproduce the material.

\section{References}

1. Venkatesh, V., Morris, M.G., Davis, G.B., Davis, F.D.: User acceptance of information technology: toward a unified view. MIS Q. 27, 425-478 (2003)

2. Ajzen, I.: The theory of planned behavior. In: van Lange, P.A.M., Kruglanski, A.W., Higgins, E.T. (eds.) Handbook of Theories of Social Psychology, pp. 438-459. SAGE Publications Ltd., London (2012)

3. Pedrotti, M., Nistor, N.: Online lecture videos in higher education: acceptance and motivation effects on students' system use. In: Sampson, D.G. (ed.) IEEE 14th International Conference on Advanced Learning Technologies (ICALT), Athens, Greece, pp. 477-479. IEEE, Piscataway, NJ, 7-10 July 2014

4. Nistor, N.: When technology acceptance models won't work. non-significant intentionbehavior effects. Comput. Hum. Behav. 34, 299-300 (2014)

5. Beachboard, M.R., Beachboard, J.C., Li, W., Adkison, S.R.: Cohorts and relatedness. Selfdetermination theory as an explanation of how learning communities affect educational outcomes. Res. High. Educ. 52, 853-874 (2011)

6. Bailey, T.H., Phillips, L.J.: The influence of motivation and adaptation on students' subjective well-being, meaning in life and academic performance. High. Educ. Res. Dev. 35, 201-216 (2015)

7. Deci, E.L., Ryan, R.M.: Self-determination theory. In: van Lange, P.A.M., Kruglanski, A.W., Higgins, E.T. (eds.) Handbook of Theories of Social Psychology, pp. 416-437. SAGE Publications Ltd., London (2012)

8. Standage, M., Duda, J.L., Ntoumanis, N.: A test of self-determination theory in school physical education. Br. J. Educ. Psychol. 75, 411-433 (2005)

9. Vallerand, R.J., Pelletier, L.G., Blais, M.R., Briere, N.M., Senecal, C., Vallieres, E.F.: The academic motivation scale. a measure of intrinsic, extrinsic, and amotivation in education. Educ. Psychol. Measur. 52, 1003-1017 (1992) 